\title{
The Effects of Incentive Regulation on Retail Telephone Service Quality in the United States
}

\author{
DAVID E. M. SAPPINGTON*
}

Department of Economics, University of Florida

\begin{abstract}
This article provides a review and critique of the empirical literature that examines the effects of incentive regulation on retail telephone service quality in the United States. The literature provides mixed findings. Some dimensions of service quality appear to improve under incentive regulation (relative to rate of return regulation) while others deteriorate. Suggestions for much-needed future research are offered.
\end{abstract}

\section{Introduction}

Many state telecommunications regulators in the United States have adopted alternatives to rate of return regulation in recent years. As Table 1 reveals, these alternatives - often referred to as "incentive regulation" - include earnings sharing regulation, rate case moratoria, and pure price cap regulation. ${ }^{1}$ Under earnings sharing regulation, the regulated firm and its customers share on an ongoing basis realized earnings that exceed target levels. Under rate case moratoria, general rate hearings that realign revenues with costs are precluded for a specified period of time. Pure price cap regulation plans specify the rate at which the firm's prices can increase over time, and do not link this rate of price increase to the rate at which the firm's costs increase during the price cap regime. ${ }^{2}$ Therefore, under pure price cap regulation, the regulated firm retains all of the incremental earnings it generates in the market place.

These forms of incentive regulation differ from rate of return (ROR) regulation, at least in principle, by allowing the earnings of the regulated firm to diverge significantly from target levels. In particular, if the regulated firm is able to generate earnings in excess of a

\footnotetext{
* Mailing address: P.O. Box 117140, Gainesville, Florida 32611. E-mail: sapping@ufl.edu I thank the editor of this Special Issue, Dennis Weisman, and an anonymous referee for helpful comments. I am also grateful to Chunrong Ai and Salvador Martinez for enlightening discussions of the issues reviewed in this article. I am particularly grateful to Vanessa Cruz for invaluable research assistance.

${ }^{1}$ The data in Table 1 are derived from State Telephone Regulation Report (2002a,b,c) and the references cited in Sappington (2002, footnote 20).

${ }^{2}$ Often, price cap regulation plans will authorize regulated prices to increase at the rate of general price inflation in the economy, less an offset, called the "X factor". See Bernstein and Sappington (1999) and Sappington (2002). Price cap regulation plans are classified as "pure" plans when they do not entail any explicit sharing of earnings.
} 
specified (target) level, the firm is permitted to keep some or all of the incremental earnings for a period of time. Consequently, incentive regulation may provide the regulated firm with greater incentive than ROR regulation to increase its revenues and reduce its operating costs.

The level of service quality the regulated firm delivers can affect both its revenues and its costs. In particular, the firm may be able to enhance its revenues by increasing the level of service quality it provides. Alternatively, the firm may be able to reduce its operating costs by reducing the level of service quality it delivers to its customers. Thus, in principle, an increased opportunity to retain incremental profit could encourage a regulated firm either to increase or to decrease the level of service quality it provides (or to increase some dimensions of service quality and reduce other dimensions). ${ }^{3}$ In this respect, economic theory does not provide unequivocal predictions regarding the effects of incentive regulation on service quality. ${ }^{4}$ Consequently, empirical research is required to provide definitive conclusions.

The purpose of this article is to review and critique empirical studies of the effects of incentive regulation on the level of service quality delivered to retail customers in the U.S. telecommunications industry. ${ }^{5}$ The focus on these studies facilities a direct comparison of the studies because they employ a comprehensive, common data set. This focus also excludes few studies of the effects of incentive regulation on service quality. Conclusions from other relevant studies are reviewed briefly in section 4. The four main studies analyzed in this article are those by Ai and Sappington (1998), Roycroft and GarciaMurrilo (2000), Banerjee (2003), and Clements (2004). These studies are hereinafter referred to as $[\mathrm{AS}],[\mathrm{RG}],[\mathrm{B}]$, and [C], respectively. ${ }^{6}$ Tardiff and Taylor's (1993) early investigation of the effects of incentive regulation on service quality is also discussed in section 3 .

This review draws three primary conclusions. First, the empirical research to date does not provide unequivocal findings regarding the effects of incentive regulation on service quality. Indeed, there is no single dimension of service quality on which all of the studies provide the same qualitative finding. Second, for many dimensions of service quality and many types of regulatory regimes, the empirical research to date identifies no significant impact of regulatory policy on telephone service quality. Unfortunately, this fact may reflect in part the limited success of the existing studies in capturing all relevant aspects of regulatory policy. Third, additional research regarding the effects of regulatory policy on the service quality delivered by regulated firms is needed. This article offers ten suggestions for how future research might proceed.

\footnotetext{
${ }^{3}$ If the provision of service quality is capital intensive and if a regulated firm reduces the capital intensity of its operations when it is no longer subject to ROR regulation, then a departure from ROR regulation may result in reduced service quality. See Spence (1975).

${ }^{4}$ Indeed, economic theory does not even provide unequivocal guidance as to whether an unregulated monopolist will deliver more or less service quality than will a perfectly competitive firm. See, for example, Spence (1975), Sheshinski (1976), and Weisman (2002).

${ }^{5}$ For related reviews of the literature that examine the effects of incentive regulation on a variety of performance dimensions, see Kridel et al. (1996), Sappington and Weisman (1996a), and Sappington (2002).

${ }^{6}$ The analysis in $[\mathrm{C}]$ is based in part on the work in Clements (2001). This review will focus on the analysis in [C], although key differences between the findings and methodologies in [C] and Clements (2001) will be noted.
} 


\begin{tabular}{|c|c|c|c|c|c|}
\hline Year & $\begin{array}{l}\text { Rate of return } \\
\text { regulation }\end{array}$ & $\begin{array}{c}\text { Rate } \\
\text { case } \\
\text { moratoria }\end{array}$ & $\begin{array}{l}\text { Earnings } \\
\text { sharing } \\
\text { regulation }\end{array}$ & $\begin{array}{c}\text { Price } \\
\text { cap regulation }\end{array}$ & Other \\
\hline 1985 & 50 & 0 & 0 & 0 & 0 \\
\hline 1986 & 45 & 5 & 0 & 0 & 0 \\
\hline 1987 & 36 & 10 & 3 & 0 & 1 \\
\hline 1988 & 35 & 10 & 4 & 0 & 1 \\
\hline 1989 & 31 & 10 & 8 & 0 & 1 \\
\hline 1990 & 25 & 9 & 14 & 1 & 1 \\
\hline 1991 & 21 & 8 & 19 & 1 & 1 \\
\hline 1992 & 20 & 6 & 20 & 3 & 1 \\
\hline 1993 & 19 & 5 & 22 & 3 & 1 \\
\hline 1994 & 22 & 2 & 19 & 6 & 1 \\
\hline 1995 & 20 & 3 & 17 & 9 & 1 \\
\hline 1996 & 15 & 4 & 5 & 25 & 1 \\
\hline 1997 & 13 & 4 & 4 & 28 & 1 \\
\hline 1998 & 14 & 3 & 2 & 30 & 1 \\
\hline 1999 & 12 & 1 & 1 & 35 & 1 \\
\hline 2000 & 8 & 1 & 1 & 39 & 1 \\
\hline 2001 & 7 & 1 & 1 & 40 & 1 \\
\hline 2002 & 8 & 1 & 1 & 38 & 2 \\
\hline
\end{tabular}

Table 1: Number of States employing the specified regulatory regime

The analysis begins in section 2 with a review of the key dimensions of service quality that are considered by $[\mathrm{AS}],[\mathrm{RG}],[\mathrm{B}]$, and [C]. Section 2 also reviews recent general trends in these dimensions of service quality. Section 3 reviews and contrasts the data and methodologies employed in [AS], [RG], [B], and [C]. The studies differ in their classification of regulatory regimes, the dependent and explanatory variables they employ, and their estimation methodologies. Section 4 reviews and contrasts the main findings in the studies. Section 5 concludes with the aforementioned suggestions for future research.

\section{Trends in retail service quality}

Telephone service quality has many dimensions. Empirical research to date has focused on four main dimensions: (1) the speed and reliability with which new service is installed; (2) 
the number of service problems reported by customers; (3) the speed with which reported problems are resolved; and (4) overall customer satisfaction. The focus on these measures is explained in part by the fact that the major local exchange carriers (LECs) are required to report their performance on these measures annually to the Federal Communications Commission via the Commission's Automated Reporting Management Information Service (ARMIS). ${ }^{7}$

The speed and reliability with which new service is installed is reflected in two performance measures. The first is the percentage of orders for installation of new service that are fulfilled by the promised (commitment) date. Figure 1 depicts the average performance of the regional Bell Operating Companies (RBOCs) on this dimension of service quality between 1991 and $2001 .^{8}$ Figure 1 reveals that the percentage of orders fulfilled by the commitment date is high, and has increased somewhat for both residential and business customers. However, the increase has not been steady over time. Indeed, the percentage of commitments kept declined in most years between 1992 and 1999, especially for business customers, but rose relatively sharply in 2000 and 2001.

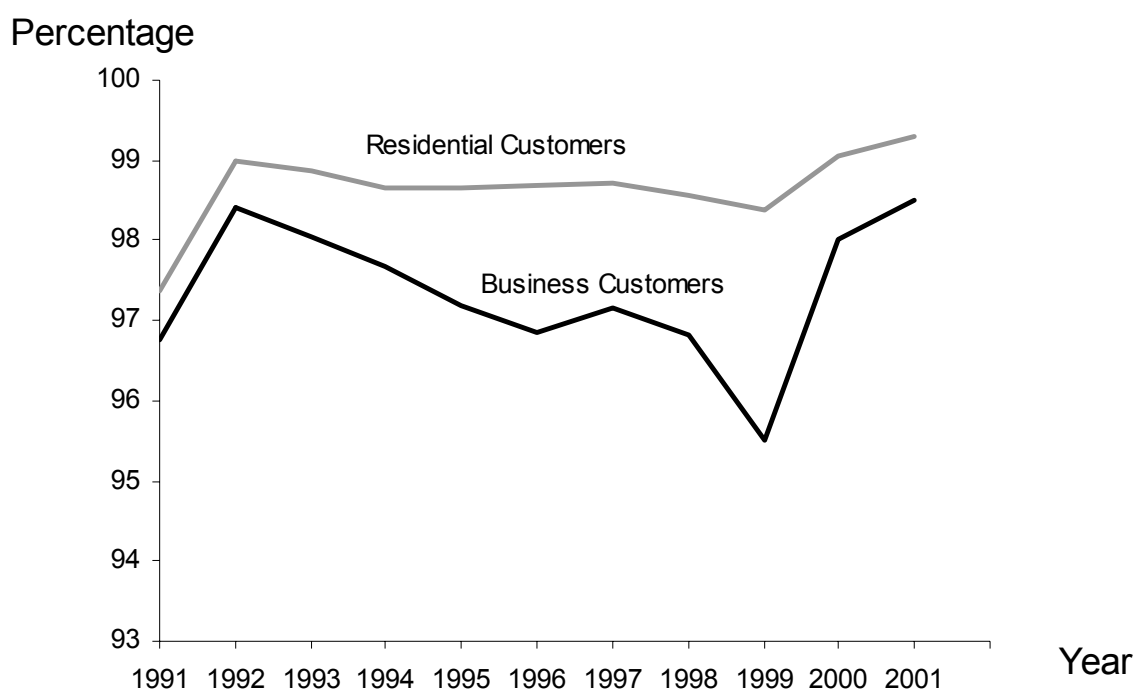

Figure 1: Percentage of installation commitments met

The second measure of the speed and reliability with which new service is installed is the average time (in business days) between when an order for the installation of new service is placed and when the new service is actually installed. This measure is arguably a better indicator of the timeliness of installation service than is the percentage of installation commitments kept. This is because the former reports the average time required to install new telephone service while the latter merely indicates success in meeting commitments that can vary across companies and over time. Thus, the firm that fulfils its commitments

${ }^{7}$ http://www.fcc.gov/wcb/armis/. Although the major LECs are required to report certain data annually to the Federal Communications Commission, these data generally are not audited by the Commission.

${ }^{8}$ The RBOCs are the largest LECs in most of the 48 contiguous states. The data that underlie Figure 1 and all subsequent figures are drawn from the ARMIS database. 
most often is not necessarily the firm that provides installations most rapidly, since the firm may only commit to install new service with a relatively long delay.

Figure 2 reveals substantial declines in the average time required to install new telephone service between 1994 (the first year the data were collected) and 2001. Residential customers, for example, were only required to wait slightly more than one day for new telephone service in 2001, compared to a wait of almost three days in 1994.

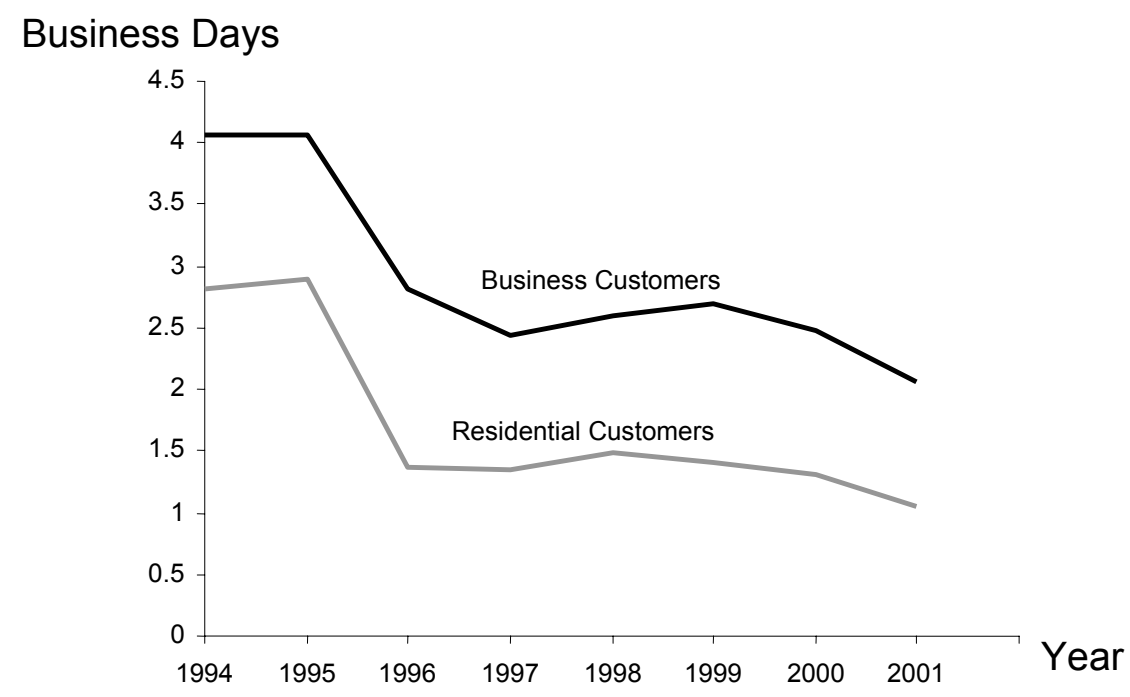

Figure 2: Time requited to install new telephone service

The second key dimension of telephone service quality - the number of service problems reported by customers - also is captured by two distinct measures: initial trouble reports and repeat trouble reports. These two types of reports of a service problem by a customer differ according to their proximity to the resolution of an earlier report of trouble by the customer. If a trouble report is received within thirty days after the resolution of an earlier report of trouble (perhaps suggesting that the earlier problem was not resolved fully), the report is counted as a repeat trouble report. Reports that are received more than thirty days after the resolution of an earlier report of a service problem are classified as initial trouble reports. ${ }^{9}$ To the extent that these two types of trouble reports reflect different dimensions of service quality, initial trouble reports may provide information about general network reliability while repeat trouble reports may serve as an indicator of the firm's efficacy in resolving problems reported by customers.

Recent experience with the average number of initial and repeat trouble reports (per 1,000 access lines) is illustrated in Figures 3 and 4, respectively. Figure 3 indicates that initial trouble reports by both residential and business customers trended downward between 1991 and 2001. The total decline during this period was almost 32\% for residential customers and nearly $41 \%$ for business customers. Figure 4 indicates that repeat trouble reports by residential customers increased by approximately $6 \%$ between 1991 and

\footnotetext{
${ }^{9}$ The telephone company, not the customer, determines whether a report of trouble has been "resolved" or "cleared". Multiple calls about the same non-resolved problem that are received within a thirty-day period are counted as a single trouble report (Kraushaar, 1999).
} 
2001, while repeat trouble reports by business customers declined by approximately $23 \%$ during this time period. ${ }^{10}$

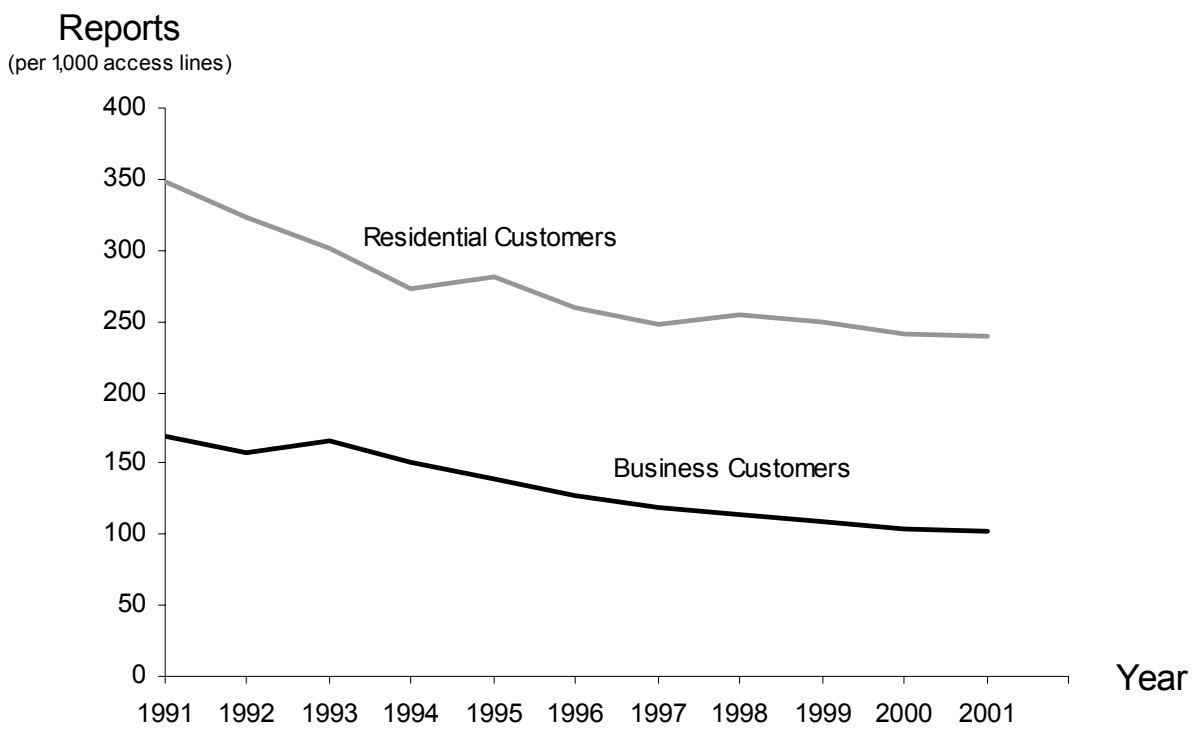

Figure 3: Number of initial trouble reports

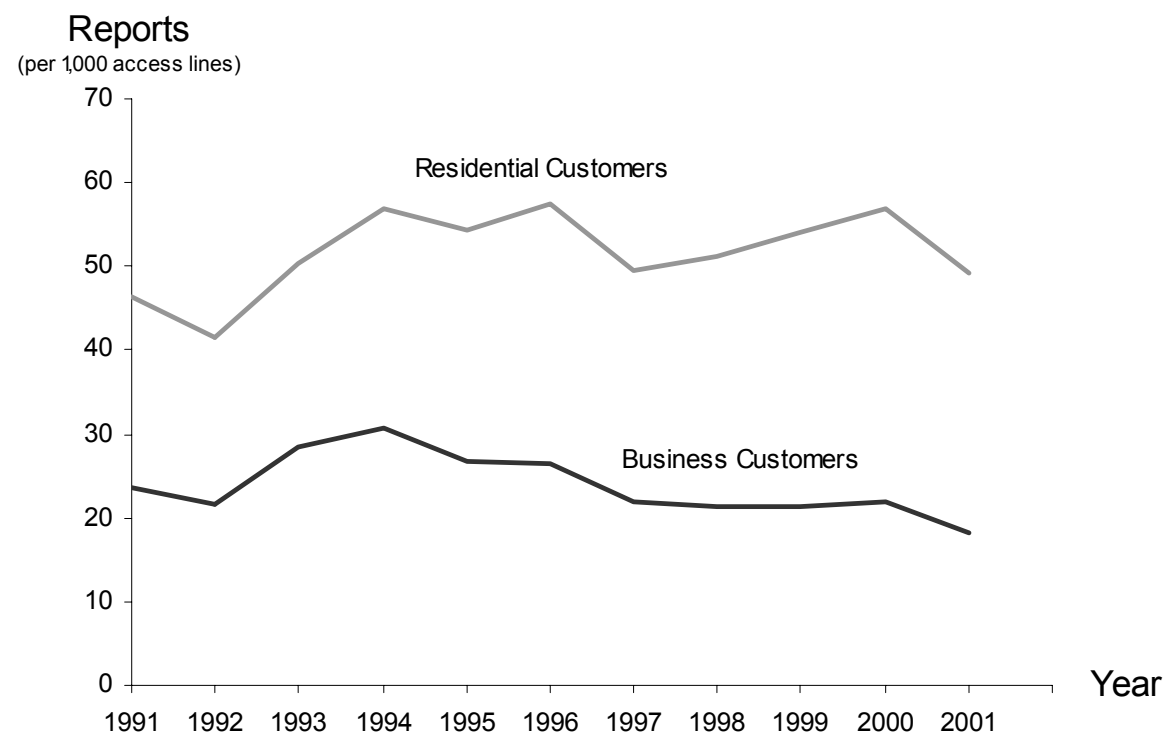

Figure 4: Number of repeat trouble reports

\footnotetext{
${ }^{10}$ Repeat trouble reports as a fraction of initial trouble reports generally have been increasing between 1991 and 2001 for both residential and business customers. The total increase over this period has been nearly $55 \%$ (from 0.133 to 0.206 ) for residential customers and almost $29 \%$ (from 0.140 to 0.180 ) for business customers.
} 
The third broad indicator of telephone service quality is the length of time (in hours) required to clear trouble reports. A trouble report is "cleared" when the telephone company determines that the reported problem no longer exists. (For example, a customer's report that his line is out of service is cleared when the customer is once again able to make and receive calls over his telephone line). Figure 5 illustrates the average amount of time required to clear trouble reports from residential and business customers between 1994 and 2001. The Figure reveals that the average delay in clearing trouble reports in 2001 was very similar to the corresponding delay in 1994 for both residential and business customers, despite substantial intra-period variation.

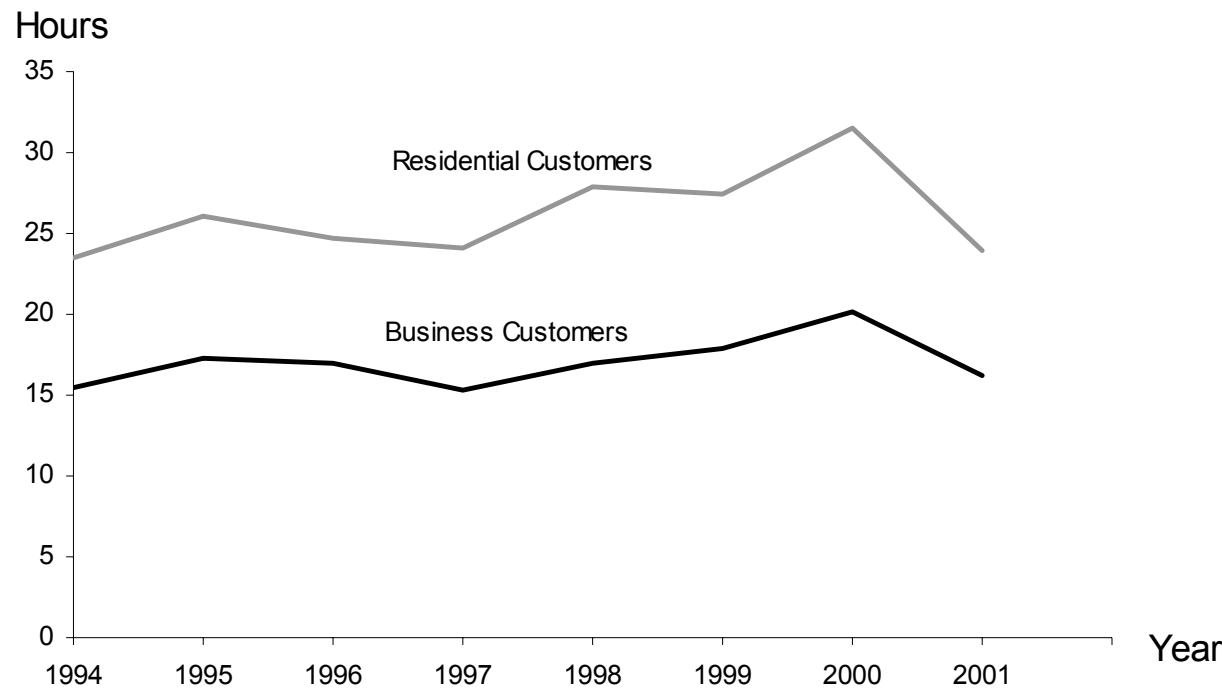

Figure 5: Time required to resolve trouble reports

The final broad measure of telephone service quality commonly employed in empirical studies is the number of service quality complaints that customers register with state and federal regulators. The ARMIS instructions state that service quality complaints do "not include complaints related to billing, operator service providers, 900 or 976 services" (ARMIS 43-05, Table V). Thus, these complaints are intended to capture customer concerns with non-financial aspects of the services delivered by the LECs (as opposed to providers of operator assistance or other pay services), and so may provide some indication of customer (dis)satisfaction with the overall level of service quality delivered by a LEC.

Figure 6 illustrates the average number of complaints to state and federal regulators per 100,000 access lines by residential and business customers. Figure 6 indicates that complaints by residential customers increased by approximately $89 \%$ between 1991 and 2001 , while complaints by business customers increased by approximately $15 \%$ during this period. Complaints from residential customers peaked in 2000 at a level that was approximately three times the corresponding level in 1991. 


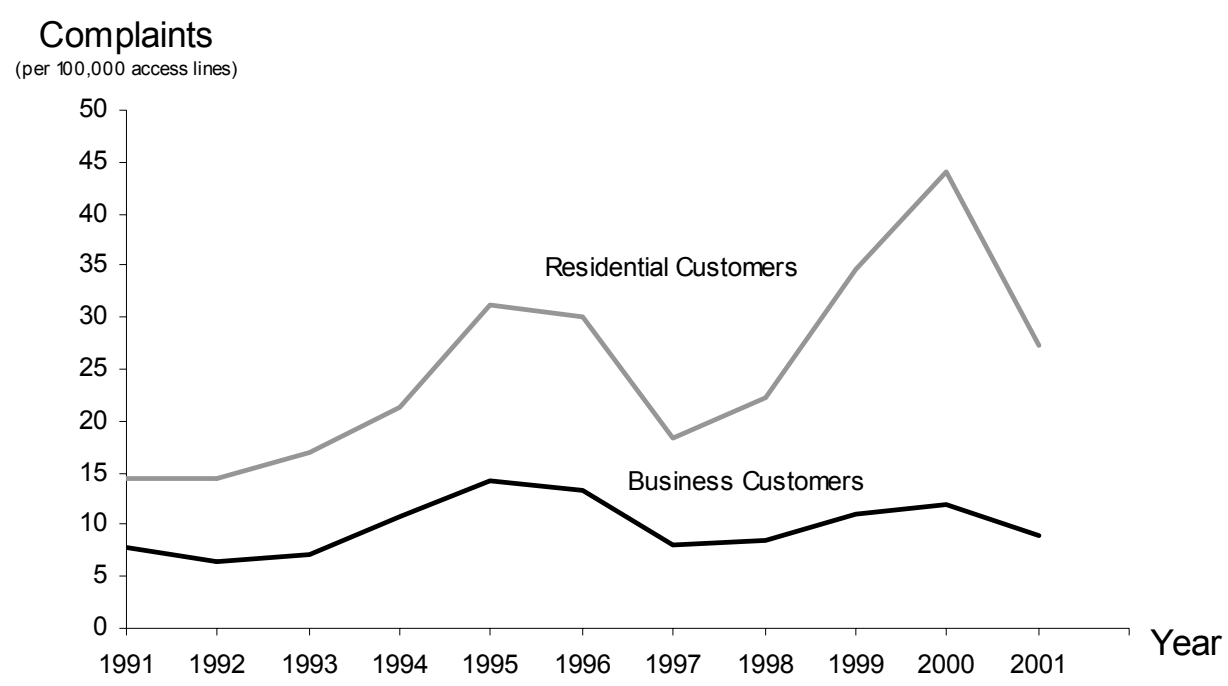

Figure 6: Complaints to State and Federal regulators

In summary, substantial variation in several dimensions of telephone service quality has been observed in the United States between 1991 and 2001. During this same period, state regulators were introducing a variety of alternatives to ROR regulation. At the level of aggregation reviewed above, it is not possible to determine whether changes in the realized levels of service quality are systematically linked to changes in regulatory regimes. Such a determination requires detailed empirical analysis.

\section{$3 \quad$ Basic data and methodology issues}

The existing empirical studies of the effects of incentive regulation on retail telephone service quality employ similar, but distinct methodologies. The purpose of this section is to review the primary similarities and differences among the methodologies. These similarities and differences concern the data sample, the dependent variables, the measures of incentive regulation, the explanatory variables, and the tests and controls for the potential endogeneity of key explanatory variables.

\subsection{Data samples}

As noted in section 2, the empirical analyses under study all employ service quality data that the major local exchange carriers file with the Federal Communications Commission (FCC). Thus, the time periods in the studies generally begin when the relevant data were first reported to the FCC. This is 1991 for most variables, as indicated in the second 
column of Table $2 .^{11,12}$ The last year of data in each study varies according to the year in which the study was undertaken.

As the third column in Table 2 reveals, most studies examine the service quality delivered by the RBOC that operates in each state, and view the entire state as the RBOC's operating territory. ${ }^{13}[\mathrm{C}]$ is an exception. $[\mathrm{C}]$ examines the service quality delivered by the largest LEC in each state, and the largest LEC is not always an RBOC. ${ }^{14}[\mathrm{C}]$ also identifies carefully the particular counties that the largest LEC serves in a state, and employs data specific to those counties when defining key explanatory variables. ${ }^{15}$ This more accurate identification of each LEC's operating territory is commendable and potentially important, since the largest LEC in a state often does not serve sizable geographic regions in the state.

\begin{tabular}{|c|c|c|c|c|}
\hline Study & $\begin{array}{l}\text { Time } \\
\text { period }\end{array}$ & $\begin{array}{l}\text { Regulated } \\
\text { firm }\end{array}$ & $\begin{array}{l}\text { Types of } \\
\text { incentive } \\
\text { regulation }\end{array}$ & $\begin{array}{l}\text { Dimensions of } \\
\text { service quality }\end{array}$ \\
\hline$[\mathrm{AS}]$ & $1992-1996$ & $\mathrm{RBOC}$ & $\begin{array}{l}\text { Rate case moratoria. } \\
\text { Earnings sharing. } \\
\text { Pure price caps. }\end{array}$ & $\begin{array}{l}\text { \% Installation commitments met. } \\
\text { Time to install new service. } \\
\text { Total trouble reports. } \\
\text { Time to clear trouble reports. } \\
\text { Complaints to Regulators. }\end{array}$ \\
\hline$[\mathrm{B}]$ & 1991-1999 & RBOC & Earnings sharing. & $\begin{array}{l}\text { Same as in [AS], plus: } \\
\text { Switch downtime. } \\
\text { Trunk blocking rates. }\end{array}$ \\
\hline$[\mathrm{C}]$ & $1992-1998$ & Largest LEC & $\begin{array}{l}\text { Non-ROR plans that } \\
\text { include no earnings } \\
\text { sharing. }\end{array}$ & $\begin{array}{l}\text { \% Installation commitments met. } \\
\text { Time to install new service. } \\
\text { Initial trouble reports. } \\
\text { Repeat trouble reports. } \\
\text { Complaints to regulators. } \\
\text { Customer satisfaction (survey). } \\
\text { Measures of network modernization. }\end{array}$ \\
\hline$[\mathrm{RG}]$ & 1991-1998 & $\begin{array}{c}\text { RBOC in } \\
\text { Ameritech, Bell } \\
\text { Atlantic, } \\
\text { NYNEX and } \\
\text { SBC territories }\end{array}$ & $\begin{array}{l}\text { Indexed price caps. } \\
\text { Other non-ROR } \\
\text { plans. }\end{array}$ & $\begin{array}{l}\text { Initial trouble reports. } \\
\text { Repeat trouble reports. }\end{array}$ \\
\hline
\end{tabular}

Table 2: A comparison of selected elements of the studies

\footnotetext{
${ }^{11}$ [AS] restrict their sample to the post-1991 period because, in the authors' view, "the data appear to be unreliable, as they contain many extreme entries that seem inconsistent with subsequent data" (footnote 43). [C] also considers only the post-1991 period. [B] reports encountering "missing and "noisy' data for 1991", but employs data from that year "after making adjustments for problematic data" (footnote 20). Kraushaar (1995, p. 193) notes apparent errors in the ARMIS service quality data "particularly in the earlier quarters."

${ }^{12} \mathrm{An}$ exception is the average time required to resolve service problems reported by customers. The major local exchange carriers only began to report these data to the FCC in 1994.

${ }^{13}$ Connecticut is an exception. Southern New England Telephone is not an RBOC. However, it is the largest LEC, and so is viewed as the relevant LEC in all studies except [RG], which excludes Connecticut from the sample. All studies exclude Alaska from their samples. [AS], [B], and [RG] also exclude Hawaii.

${ }^{14}$ Clements (2001) reports that Sprint/United is the largest LEC in Nevada.

${ }^{15}$ Clements (2001) describes the precise manner in which RBOC territories are approximated.
} 


\subsection{Dependent variables}

As indicated in the last column in Table 2, [AS], [B], and [C] all examine the effects of incentive regulation on the speed and reliability with which new telephone service is installed, the number of trouble reports, the time required to clear trouble reports, and customer complaints to regulators about service quality. ${ }^{16}[\mathrm{RG}]$ focus exclusively on trouble reports.

The studies employ different measures of trouble reports. [AS] and [B] sum initial and repeat trouble reports, and subtract incidents in which the LEC found no problem when it investigated the customer report of a service problem. [C] and [RG] analyze initial and repeat trouble reports separately, and express the latter as a fraction of the former. The approach adopted by $[\mathrm{C}]$ and $[\mathrm{RG}]$ enables the authors to determine whether initial trouble reports and repeat trouble reports exhibit distinct trends (as Figures 3 and 4 suggest they may).

[B] also examines the impact of incentive regulation on the extent of network switch outages, as measured by the ratio of the aggregate number of minutes for which network switches were not operating to the total number of dial equipment minutes of service provided by the regulated firm. One potential problem with this measure of switch downtime is that it counts scheduled and unscheduled switch downtime symmetrically. To the extent that scheduled downtime occurs when maintenance and repair are being performed, higher levels of scheduled downtime may reflect attempts to ensure higher, not lower, levels of network reliability and service quality.

In addition, $[\mathrm{B}]$ investigates the impact of incentive regulation on network congestion, as measured by the percentage of trunks exceeding design blocking objectives for three consecutive months. Trunks are the cables that carry traffic between major switches in a network. Some telephone calls are blocked (that is, not completed) if the number of calls routed over a trunk exceeds the trunk's capacity. When calls are blocked, customers must re-dial their calls, and may face non-trivial delays in completing their calls. Thus, call blockage rates can serve as useful indicators of a relevant dimension of telephone service quality. However, to the extent that design blocking objectives differ across trunks, companies, and/or time, the particular measure of call blocking employed in [B] (which is the measure that the major LECs report to the FCC) may complicate inferences about the effects of incentive regulation on this dimension of service quality.

[C] also analyzes the effects of incentive regulation on an overall measure of customer satisfaction with their telephone service. This measure is derived from customer surveys. To the extent that these surveys differ across LECs and over time, it can be difficult to draw inferences from these data about the effects of incentive regulation on "customer satisfaction".

[C] views the speed and reliability with which new telephone service is installed, repeat trouble reports, customer complaints to regulators, and overall customer satisfaction levels as indicators of "people and process oriented" quality. [C] views initial trouble reports and various measures of network modernization as indicators of "equipment and system oriented" quality. The measures of network modernization that [C] analyzes include the fraction of network cable that is fiber and the fraction of network access lines that are served by digital switches (as opposed to older analogue switches). These

\footnotetext{
${ }^{16}[\mathrm{~B}]$ and $[\mathrm{C}]$ count complaints filed with either federal or state regulators. [AS] only count complaints filed with state regulators.
} 
dimensions of infrastructure modernization may affect realized levels of service quality, as discussed further below. Whether they are compelling measures of service quality in and of themselves remains an open question.

\subsection{Characterizing regulatory policy}

As noted in the introduction, the states have employed a variety of alternatives to rate of return (ROR) regulation in recent years. The empirical studies reviewed in this article adopt different definitions of "incentive regulation", as the fourth column in Table 2 indicates. $[\mathrm{AS}]$ treat earnings sharing regulation, rate case moratoria, and pure price cap regulation as three distinct alternatives to ROR regulation, and examine the effects of each of these alternatives on realized levels of service quality. [B] views earnings sharing as one distinct alternative to ROR regulation, and all other regulatory mechanisms combined (including rate case moratoria and pure price cap regulation) as another distinct alternative. [B] includes price cap regulation plans that entail some sharing of earnings in both the "earnings sharing" and the "other incentive regulation" categories.

$[\mathrm{RG}]$ also consider two alternatives to ROR regulation. The first comprises all indexed price cap plans, in which the authorized rate of price increase is linked explicitly to a general measure of price inflation, such as the retail price index. The second consists of other alternatives to ROR regulation (such as rate case moratoria) that do not index prices to inflation. $[\mathrm{RG}]$ do not explain in detail why indexed and non-indexed price regulation plans might be expected to induce systematically different levels of service quality.

[C] divides the state regulatory plans into two mutually exclusive categories: ROR regulation and non-ROR regulation. Earnings sharing plans are included in the former category. Price-based plans (including rate case moratoria and substantial deregulation) are included in the latter category. ${ }^{17}$ Thus, in contrast to the other studies, [C] implicitly assumes that a regulatory plan that encompasses any earnings sharing has effects on service quality comparable to those of ROR regulation. ${ }^{18}$

None of the studies reviewed here differentiates among regulatory plans according to the service quality standards and associated penalty and reward structures that the plans encompass. ${ }^{19}$ If the available data would permit such differentiation, distinctions might be drawn, for example, between the effects of: (1) a price cap regulation plan that imposes demanding service quality standards and specifies harsh penalties for failure to meet the standards; and (2) a price cap regulation plan that imposes no service quality standards. ${ }^{20}$

Tardiff and Taylor [TT] (1993) provide useful differentiation in this regard. [TT] divide states with incentive regulation plans in 1990 into two categories: (1) plans that include service quality standards; and (2) plans that do not include quality standards. The authors then compare firms on the basis of an index of service quality variables. ${ }^{21}$ [TT]

\footnotetext{
${ }^{17}$ The studies classify regulatory plans using a variety of sources, including Abel and Clements (1998) and State Telephone Regulation Report (2002 a,b,c).

${ }^{18}$ In principle, it is preferable to test this assumption than to impose it. However, as indicated below, [B]'s findings lend some support to the assumption maintained in [C].

${ }^{19}$ Clements (2001) introduces as an explanatory variable a binary indicator of whether the state regulatory commission has ever imposed a financial penalty on the firm for poor service quality.

${ }^{20}$ Failure to characterize fully the service quality requirements imposed by an incentive regulation plan can make it difficult to distinguish between effects that are motivated by the plan and those that are mandated by the plan. See Sappington and Weisman (1996a, 280-283; 1996b).

${ }^{21}[\mathrm{TT}]$ report that the index is based on the same ARMIS service quality data employed by the other studies reviewed here. However, little detail is provided regarding the composition of this index.
} 
report that although realized service quality was highest in 1990 in states with no incentive regulation plan, service quality improved the most between 1990 and 1991 in states with incentive regulation plans that included quality standards. [TT] also report that among states with incentive regulation plans in 1990, realized service quality was higher in states with no service quality standards than in states with service quality standards. ${ }^{22}$

\subsection{Explanatory variables}

The key explanatory variables are the regulatory regime variables. $[\mathrm{B}]$ and $[\mathrm{C}]$ implicitly assume that any effects of incentive regulation take time to materialize. They do so by including among the explanatory variables the regulatory regime variables lagged one year. In contrast, $[\mathrm{AS}]$ and $[\mathrm{RG}]$ employ as explanatory variables the contemporaneous regulatory regime variables. The contemporaneous effects thereby presumed might be justified on the grounds that: (1) a new regulatory regime is often anticipated well before it is implemented and; (2) annual service quality data typically reflects average performance over an entire year, and thus can incorporate some lagged effects of the regulatory regime. However, when possible, it generally is preferable to allow for lagged effects of regulatory policy, and to let the data reveal the strength of these effects.

[AS] and [C] include year-specific and state-specific dummy variables in their estimating equations, thereby employing a dynamic fixed-effects methodology. The yearspecific dummy variables capture the effects of macroeconomic factors (such as industrywide technological advances and federal telecommunications regulations) that vary over time, but do not vary across states or firms. The state-specific dummy variables capture features of the regulated firm, the state in which it operates, and the regulatory environment (such as persistent operating procedures and legislation) that do not vary over time. Together, these dummy variables account for a variety of economic, social, and political determinants of telephone service quality that are difficult to capture more directly. Because these dummy variables turn out to be highly correlated with many demographic variables (especially those that change little or trend systematically over time), $[\mathrm{AS}]$ and $[\mathrm{C}]$ omit many common demographic variables (for example, population, income, wages). This approach avoids multicollinearity problems, but may introduce omitted variable bias.

[B] includes year-specific, but not state-specific, dummy variables, and adopts a random-effects rather than a fixed-effects methodology. Thus, [B] does not control explicitly for unspecified, persistent, state-specific forces that may influence realized levels of service quality, and so may introduce the possibility of omitted variable bias. [B]'s approach does conserve on degrees of freedom, though. [RG] incorporate neither yearspecific nor state-specific dummy variables, despite identifying what appear to be systematic trends in the data over time.

Competition is an important potential determinant of realized service quality that varies over time and across states. As Clements (2001) explains in detail, an incumbent supplier may increase service quality in order to compete more effectively for customers even though a monopolist would implement lower levels of service quality under otherwise

\footnotetext{
${ }^{22}$ Higher levels of service quality might be associated with the absence of explicit service quality standards if regulators impose explicit standards when they find realized service quality to be inappropriately low in the absence of standards.
} 
identical conditions. ${ }^{23}$ Thus, empirical investigations of the effects of incentive regulation on service quality should control for the extent of industry competition. ${ }^{24}$ Unfortunately, good measures of the intensity of competition are difficult to find. [B] employs as a primary measure of local competition (that is, competition among local exchange carriers) the number of competitors that have received telephone numbers that they can assign to customers. [RG] also employ a measure of the number of active local exchange carriers. These measures may accurately capture the intensity of competition if this intensity is proportional to the number of competitors (as opposed to their market share, revenues, etc.).

[C]'s proxy for local competition is the percentage of telephone numbers that are assigned to competitive local exchange carriers. To the extent that the number of telephone numbers that a firm holds is a reasonable proxy for the number of customers that it presently services or soon will serve, this measure may better capture the intensity of local competition than does a simple count of the number of active competitors.

[AS] attempt to capture the intensity of local competition with a measure of the number of miles of fiber optic cable that competitive access providers have installed in the state. As [B] suggests, this measure may reflect potential local competition (particularly potential competition for large-volume, business customers) more accurately than it reflects actual local competition. ${ }^{25}$

[AS] and [B] also control for the presence or absence of intraLATA toll competition. LATAs are geographic regions within which the RBOCs are permitted to provide toll services. In some states, regulators shielded the RBOCs from toll service competition for a time, often so that the profit the RBOC derived from toll services could be used to support high-quality, low-priced basic local service.

Because various dimensions of telephone service quality may be influenced by the physical characteristics of the telecommunications network, [AS], [B], and [RG] include among their explanatory variables a measure of network modernization. [AS] and [B] employ the fraction of access lines that are served by digital switches. [RG] employ the fraction of network switches that are digital and the fraction of network cable that is fiber optic (as opposed to copper) cable. As noted above, [C] views these dimensions of network modernization as measures of service quality, and so treats them as dependent variables. $[\mathrm{C}]$ does not employ indicators of network modernization as explanatory variables.

\subsection{Endogeneity of the regulatory regime}

To identify accurately the effects of incentive regulation on service quality, the potential endogeneity of the regulatory regime should be considered. It is conceivable, for example, that regulators are willing to implement incentive regulation primarily when they are confident that service quality will improve over time under any regulatory regime. An

\footnotetext{
${ }^{23}$ In light of this observation, Clements (2001) runs separate regressions for two distinct segments of the data: one in which the incumbent LEC faces no competition and another in which the incumbent LEC faces competition in its operating territory. A LEC is classified as facing no competition in a state in a given year if the number of competitive LEC s operating in the (relevant portions of the) state in the preceding year was identically zero. Otherwise, the LEC is classified as facing competition.

${ }^{24}$ Ideally, these empirical studies also should account for the possible endogeneity of the level of industry competition. The level of realized competition may depend upon the prevailing regulatory regime, the level of service quality delivered by the incumbent supplier, and many other variables.

${ }^{25}$ Dennis Weisman has suggested that requests by incumbent suppliers to reduce their service prices might provide additional information about the intensity of local competition.
} 
observed correlation between incentive regulation and improved service quality in such a setting does not necessarily provide evidence that the implementation of incentive regulation enhances service quality. [AS] test for the potential endogeneity of the regulatory regime, and report that they cannot reject the null hypothesis of no endogeneity of the regulatory regime. [C] explicitly resolves the potential endogeneity problem in his sample. Following the methodologies employed in Ai and Sappington (2002) and Donald and Sappington $(1995,1997),[\mathrm{C}]$ develops instruments for the (lagged) regulatory regime variables and employs these instruments in place of the regime variables themselves.

\section{$4 \quad$ Findings}

Some of the key qualitative conclusions drawn in these studies are summarized in Table 3. The five primary measures of service quality are listed in the first row of the Table. All measures are defined as service quality problems. Therefore, an arrow that points upward in the Table indicates that incentive regulation is associated with increased service quality problems, or reduced service quality. In contrast, an arrow that points downward indicates a reduction in service quality problems, or an increase in service quality. A flat line denotes a finding of no significant effect of incentive regulation on service quality. ${ }^{26}$

The four studies are listed in the first column of Table 3. The designation "Nonearnings sharing" under [B] indicates that [B]'s findings reported in the third row of Table 3 pertain only to incentive regulation plans that impose no earnings sharing provisions. [B] identifies no significant effects on service quality of incentive regulation plans that involve earnings sharing. ${ }^{27}$

Table 3 presents a mixed assessment of the effects of incentive regulation on telephone service quality. No systematic impact is evident. A simple count shows six instances in which service quality declines under incentive regulation, four instances in which service quality increases, and six instances where incentive regulation has no significant effect on service quality.

Table 3 also reveals little consensus among the studies. Notice, in particular, that there is no column in Table 3 that contains identical symbols for all studies. Furthermore, the arrows point in opposite directions in two of the five relevant columns. Although there are three columns in which arrows do not point in opposite directions, a comparison across columns still suggests a lack of consensus. In particular, while [B] reports a smaller percentage of installation commitments kept under incentive regulation, ${ }^{28}$ [AS] report the

\footnotetext{
${ }^{26}$ Table 3 summarizes estimated effects that are significantly different from zero at the $5 \%$ level or below. To simplify the exposition, Table 3 does not present: (1) [C]'s findings regarding the effects of incentive regulation on network modernization and customer satisfaction; and (2) [B]'s findings regarding the effects of incentive regulation on switch downtime and trunk blockage rates. [B] reports no significant variation in switch downtime or trunk blockage rates according to the prevailing regulatory regime. [C] reports an analogous conclusion regarding customer satisfaction. [C], like Greenstein et al. (1995) and Ai and Sappington (2002), among others, conclude that incentive regulation is associated with significant increases in network modernization.

${ }^{27}$ Similarly, [AS] find no significant effects of the incentive regulation plans that are not explicitly identified in the second row of Table 3. For example, [AS] find no significant effect of earnings sharing regulation or price cap regulation on the average time required to install new telephone service.

${ }^{28}$ Clements (2001) also finds a smaller percentage of installation commitments kept under incentive regulation between 1991 and 1999 when the regulated LEC faces no competitors.
} 
arguably contradictory finding that the average time required to install new telephone service is lower under rate case moratoria than under ROR regulation.

\begin{tabular}{|c|c|c|c|c|c|}
\hline $\begin{array}{c}\text { Study } \\
\text { (subsample) }\end{array}$ & $\begin{array}{c}\% \text { Installation } \\
\text { commitments } \\
\text { missed }\end{array}$ & $\begin{array}{c}\text { Average } \\
\text { installation } \\
\text { time } \\
\end{array}$ & $\begin{array}{l}\text { Trouble } \\
\text { reports }\end{array}$ & $\begin{array}{l}\text { Average time } \\
\text { to clear } \\
\text { trouble reports }\end{array}$ & $\begin{array}{l}\text { Complaints } \\
\text { to regulators }\end{array}$ \\
\hline [AS] & - & $\underset{(\mathrm{RCM})}{\downarrow}$ & $\uparrow_{(\mathrm{ESR})}^{\uparrow}$ & $\begin{array}{c}\uparrow \\
(\mathrm{PCR}, \mathrm{RCM}) \\
\end{array}$ & $\underset{(\mathrm{PCR}, \mathrm{ESR}, \mathrm{RCM})}{\downarrow}$ \\
\hline $\begin{array}{c}{[\mathrm{B}]} \\
\text { (Non-earnings } \\
\text { sharing) } \\
\end{array}$ & $\uparrow$ & - & $\downarrow$ & - & $\uparrow$ \\
\hline$[\mathrm{C}]$ & - & - & $\uparrow_{\text {(Repeat) }}^{\uparrow}$ & - & $\uparrow$ \\
\hline$[\mathrm{RG}]$ & & & $\underset{\text { (Initial, PCR) }}{\downarrow}$ & & \\
\hline
\end{tabular}

Table 3: Significant effects of incentive regulation on retail service quality

$\mathrm{RCM}=$ Rate case moratoria; ESR $=$ Earnings sharing regulation; $\mathrm{PCR}=$ Price cap regulation

The apparent conflict in the findings of [B] and [C] with regard to trouble reports (as reflected in the fourth column of Table 3) may stem from the different definitions employed in the two studies. [B] reports a decline in total (initial plus repeat) trouble reports under incentive regulation, while [C] reports a corresponding increase in repeat trouble reports. These findings are mutually consistent with a decline in initial trouble reports and an increase in repeat trouble reports. ${ }^{29}$

$[\mathrm{RG}]$ report a decline in initial trouble reports under indexed price cap regulation. ${ }^{30}$ In contrast, $[R G]$ report an increase in repeat trouble reports in some territories (NYNEX) and a decrease in other territories (Ameritech, Bell Atlantic, and SBC) under indexed price cap regulation. ${ }^{31}[\mathrm{RG}]$ suggest that more modern networks may malfunction less often, but are more difficult to repair when they do malfunction. A lower incidence of malfunction could result in fewer initial trouble reports, while an increased difficulty in effecting repairs could lead to more repeat trouble reports. It would be useful to determine if the association between incentive regulation and increased repeat trouble reports that $[\mathrm{C}]$ identifies would persist in the presence of an explicit control for the degree of network modernization.

The estimated magnitudes of the significant qualitative effects identified in Table 3 vary by study and by service quality dimension. To illustrate, [AS] estimate that the reduction in average installation time under rate case moratoria relative to ROR regulation exceeds two business days (which is approximately half of the average installation time). This number is surprisingly large, as is its significance, given the short period of time

\footnotetext{
${ }^{29}$ Recall that repeat trouble reports are expressed as a fraction of initial trouble reports in [C]'s analysis. Therefore, measured performance on this dimension declines as the number of initial trouble reports declines, for a fixed number of repeat trouble reports.

${ }^{30}$ The decline is significant in Bell Atlantic states, but insignificant in other states.

${ }^{31}[\mathrm{RG}]$ present mixed findings regarding the effects of other forms of incentive regulation on both initial and repeat trouble reports. Because [RG] analyze the experience in the Ameritech, Bell Atlantic, NYNEX, and SBC territories separately, the authors are unable to draw many general conclusions regarding the effects of incentive regulation on initial or repeat trouble reports.
} 
(1994 - 1996) for which data on this measure of service quality is available in [AS]'s sample. ${ }^{32}$ It is conceivable that demonstration effects are at play during this time period. Rate case moratoria often serve as transitions to other regulatory regimes. To ensure the future adoption of favorable regulatory regimes, a firm may be sure to deliver exceptional service quality under rate case moratoria. To the extent that such demonstration effects operate and are not controlled for adequately, estimates of favorable effects of rate case moratoria may be overstated. ${ }^{33}$

[C] estimates that repeat trouble reports are approximately $15 \%$ higher under incentive regulation than under ROR regulation and earnings sharing. [B] reports a comparable decline in total (initial plus repeat) trouble reports by both residential and business customers under incentive regulation plans that do not involve earnings sharing. As noted above, these two sets of findings could be consistent with a decline in initial trouble reports and an increase in repeat trouble reports under some forms of incentive regulation.

[AS] find that trouble reports by residential customers are approximately $14 \%$ higher under earnings sharing regulation than under ROR regulation. This conclusion suggests that earnings sharing plans may provide qualitatively different incentives for firms to deliver service quality than does ROR regulation. In contrast, [B]'s finding of no significant differences between the effects of earnings sharing regulation and ROR regulation support [C]'s approach of treating these two types of regulatory policies as a single regulatory regime.

[AS] report substantially longer lags (exceeding 20\%) in clearing trouble reports by residential customers under price cap regulation than under ROR regulation. The differential lag is even greater (exceeding 30\%) for both residential and business customers under rate case moratoria. These findings may be an artifact of the short time period in [AS]'s study, since [B] and [C] find no significant effects of incentive regulation on the time required to clear trouble reports.

The same may be true of [AS]'s finding of large reductions (exceeding 30\%) in complaints to the public service commission under price cap regulation, earnings sharing regulation, and rate case moratoria. [B]'s finding of comparable increases in complaints by business customers to state and federal regulators and [C]'s finding of comparable increases in the combined complaints of residential and business customers under incentive regulation plans that do not entail earnings sharing suggest that the early pattern identified in [AS] did not persist beyond 1996..$^{34,35}$

Before concluding, the findings of an important related study by Zimmerman [Z] (2003) are summarized briefly. While the studies summarized in Table 3 focus on the effects of incentive regulation on service quality provided to retail customers, [Z] analyzes the effects of incentive regulation on service quality delivered to interexchange carriers

\footnotetext{
${ }^{32}$ [AS] begin their analysis of this variable in 1994 because its definition changes in the ARMIS instructions after 1993. Before 1994, the delay in installing new telephone service was measured relative to the time the new service was promised (that is, the commitment date). After 1993, the delay is measured relative to the time the new service was requested by the customer.

${ }^{33}$ See Sappington and Weisman (1996a, 283-286; 1996b) for additional thoughts on how demonstration effects can complicate empirical analyses.

${ }^{34}$ The Telecommunications Act (47 U.S.C. 151 et seq.) which opened the telecommunications industry to widespread competition, was passed in 1996. The ensuing changes in regulatory and competition policy could, in principle, introduce new relationships between incentive regulation and service quality. Recall also from Figure 6 that complaints to federal and state regulators peaked after 1996.

${ }^{35} \mathrm{Clements}(2001)$ does not find any significant effects of incentive regulation on complaints to regulators.
} 
(IXCs). IXCs require access to LEC networks to complete long distance telephone calls for their customers. Like retail customers, IXCs value the rapid installation of new connections, report network problems to LECs, and can complain to regulators if they are dissatisfied with the service they receive from LECs. [Z] examines whether RBOC performance varies systematically on any of these dimensions of service quality according to the type of regulatory regime under which the firm operates. [Z] reports no significant variation. $^{36}$

\section{$5 \quad$ Conclusions}

Much like the associated theoretical research, empirical research regarding the effects of incentive regulation on telephone service quality does not provide unequivocal conclusions. The empirical research provides mixed findings about the effects of incentive regulation on both specific measures of service quality (for example, trouble reports) and general potential indicators of service quality (for example, customer complaints to regulators). The findings vary with both the time period and the types of incentive regulation plans under consideration.

The absence of an empirical consensus regarding the effects of incentive regulation on telephone service quality suggests the need for additional empirical research. Future research will have the benefit of a longer times series of data. Future research can also benefit from the lessons drawn from the studies reviewed in this article. Ten such lessons are identified briefly, in closing.

First, finer classifications of regulatory plans would be valuable. In particular, it is important to identify the extent to which regulatory plans specify quality standards and associated penalties for failure to achieve the standards. All relevant details of regulatory plans must be accounted for before one can draw definitive links between observed behavior and the prevailing regulatory regime.

Second, the potential endogeneity of explanatory variables merits careful consideration. As noted above, [C] (alone) employs instruments for the regulatory regime variables. However, neither [C] nor any of the other studies controls explicitly for the potential endogeneity of the extent of competition or for other key explanatory variables, such as the size of the regulated firm's work force. ${ }^{37}$ Such controls are important in order to avoid endogeneity bias. More generally, estimation of a system of equations may be needed to capture key interactions among variables. To illustrate, the system of equations might explain simultaneously the choice of regulatory regime, the nature and intensity of competition, staffing levels within the regulated firm, and service quality.

Third, better measures of competition are needed. A simple count of the number of competitors is unlikely to reflect accurately the intensity of competition that an incumbent LEC faces. Explicit measures of the market activity (for example, annual sales or number of customers) and/or the capacity of competitive LECs are needed to allow one to distinguish clearly between the effects of incentive regulation and the effects of competition.

\footnotetext{
${ }^{36}[Z]$ 's primary focus is on whether the service quality that RBOCs deliver to IXCs in a state declines after the RBOC receives approval to offer originating long distance service in the state. [Z] reports some evidence of such declines in service quality.

${ }^{37}$ The firm's work force is a key explanatory variable in [C]'s analysis of people and process oriented quality.
} 
Fourth, interactions between competition and regulatory policy warrant careful investigation. The effects of a given regulatory policy may vary substantially as the intensity of industry competition changes. Differential effects of this sort cannot be captured in regressions that implicitly assume the effects of competition and regulatory policy to be additive. ${ }^{38}$

Fifth, more generally, alternative econometric specifications warrant consideration and testing. The analyses to date typically presume a particular functional form for the regression equations, and do not (explicitly) consider and test alternative formulations. More general approaches merit consideration, including non-parametric estimation, when the data permit.

Sixth, alternative lag structures should be analyzed. The analyses to date generally assume that the regulatory regime affects contemporaneous service quality or affects service quality with a one-year lag. Alternative lag structures may be more compelling. ${ }^{39}$ For example, the strength of the effect of a regulatory regime on service quality may increase gradually over several years. Alternatively, the influence of a new regime may increase over time during the initial years of the regime, and then decline with time, perhaps as the scheduled review of the regime draws closer. ${ }^{40}$

Seventh, a richer set of explanatory variables could help to better isolate the effects of incentive regulation on telephone service quality. For example, severe weather (hurricanes or tornadoes) or strong earthquakes may cause service disruptions that affect measured service quality. If such phenomena vary over time and occur disproportionately in states that practice a particular form of regulatory policy, their absence in estimating equations may cause their effects to be viewed erroneously as a consequence of regulatory policy.

Eighth, cross-state effects might be modeled explicitly. A firm that hopes to gain regulatory approval for some form of incentive regulation in state B may work exceptionally hard to ensure that it delivers excellent service quality under the same regulatory regime in state $\mathrm{A}$, knowing that regulators in state $\mathrm{B}$ will be monitoring its performance in state A. Careful analysis of the dynamic pattern of regulatory regime adoption across the states within the operating region of each RBOC could capture any such "demonstration effects" that may be operating.

Ninth, the effects of regulatory policy on service quality in the U.S. telecommunications industry might be compared with the corresponding effects in other countries, and perhaps in other industries. Cross-country studies often are complicated by data compatibility issues, but still can provide useful insights. Given the growing use of incentive regulation in the electric power industry, ${ }^{41}$ cross-industry comparisons may be feasible soon. Cross-country and cross-industry comparisons may provide useful insights regarding how institutional characteristics (such as the commitment powers of regulators), operating technologies, and customer preferences affect the impact of incentive regulation on service quality.

\footnotetext{
${ }^{38}$ In contrast to [C] (and the other studies reviewed in this article), Clements (2001) includes among his explanatory variables an interaction term between the competition and regulatory regime variables. Ai and Sappington (2002) find that such an interaction term is often important in explaining the effects of incentive regulation on measures of performance other than service quality.

${ }^{39}$ Of course, long lag structures can introduce multicollinearity problems when the regulatory regime changes infrequently.

${ }^{40}$ See Di Tella and Dyck (2002) for evidence of such a pattern of measured effects of price cap regulation.

${ }^{41}$ See, for example, Sappington et al. (2001).
} 
Tenth, and finally, an ideal test of the effects of incentive regulation on telephone service quality would employ data that is audited and verified by an entity other than the regulated firm. As noted above, the ARMIS data on which the U.S. studies are based generally are not audited and verified by an independent entity. Some state regulatory commissions collect, audit, and verify service quality data. However, these data generally are not directly comparable across states. ${ }^{42}$ Although it is unlikely that comprehensive, systematic, audited service quality data will be available in the United States in the near future, it may ultimately be available in other countries.

\section{$6 \quad$ References}

Abel, J. and M. Clements (1998) "A Time Series and Cross-Sectional Classification of State Regulatory Policy Adopted for Local Exchange Carriers," National Regulatory Research Institute.

Ai, C. and D. Sappington (1998) "The Impact of State Incentive Regulation On the U.S. Telecommunications Industry," University of Florida, December.

Ai, C. and D. Sappington (2002) "The Impact of State Incentive Regulation On the U.S. Telecommunications Industry," Journal of Regulatory Economics, 22: 133-159.

Banerjee, A. (2003) "Does Incentive Regulation "Cause" Degradation of Retail Telephone Service Quality?” Information Economics and Policy, 15: 243-269.

Bernstein, J. and D. Sappington (1999) "Setting the $X$ Factor in Price Cap Regulation Plans," Journal of Regulatory Economics, 16: 5-25.

Clements, M. (2001) "Local Telephone Quality of Service: The Impact of Regulation and Competition," Ohio State University Ph.D. Dissertation.

Clements, M. (2004) "Local Telephone Quality of Service: A Framework and Empirical Evidence," Telecommunications Policy, forthcoming.

Clements, M. and V. Witkind-Davis (1998) "Recent Developments in Telecommunications Service Quality Regulation," NRRI Quarterly Bulletin, 19: 269-280.

Di Tella, R. and A. Dyck (2002) "Cost Reductions, Cost Padding and Stock Market Prices: The Chilean Experience With Price Cap Regulation," Harvard Business School, mimeo, October.

Donald, S. and D. Sappington (1995) "Explaining the Choice Among Regulatory Plans in the U.S. Telecommunications Industry," Journal of Economics and Management Strategy, 4: 237-265.

\footnotetext{
${ }^{42}$ See, for example, National Association of Regulatory Utility Commissioners (1992), Clements and Witkind-Davis (1998), and [C].
} 
Donald, S. and D. Sappington (1997) "Choosing Among Regulatory Options in the United States Telecommunications Industry," Journal of Regulatory Economics, 12: 227-243.

Greenstein, S., S. McMaster, and P. Spiller (1995) "The Effect of Incentive Regulation on Infrastructure Modernization: Local Exchange Companies' Deployment of Digital Technology," Journal of Economics and Management Strategy, 4: 187-236.

Kraushaar, J. (1995) "Quality of Service Measurement and the Federal Communications Commission," in Quality and Reliability of Telecommunications Infrastructure, ed. W. Lehr, 187-211. Mahwah, NJ: Lawrence Erlbaum Associates.

Kraushaar, J. (1999) Quality of Service of the Local Operating Companies Aggregated to the Holding Company Level: 1996-1998. Federal Communications Commission, Industry Analysis Division, Common Carrier Bureau, December.

Kridel, D., D. Sappington, and D. Weisman (1996) "The Effects of Incentive Regulation in the Telecommunications Industry: A Survey," Journal of Regulatory Economics, 9: 269306.

National Association of Regulatory Utility Commissioners (1992) Telephone Service Quality Handbook. (Prepared for the Committee on Communications by the Staff Subcommittee on Telephone Service Quality.) Washington, D.C., March.

Roycroft, T., and M. Garcia-Murrilo (2000) "Trouble Reports as an Indicator of Service Quality: The Influence of Competition, Technology, and Regulation," Telecommunications Policy, 24: 947-967.

Sappington, D. (2002) Price Regulation. In M. Cave, S. Majumdar, and I. Vogelsang. (eds.), The Handbook of Telecommunications Economics. Volume I: Structure, Regulation, and Competition: 225-293. Amsterdam: Elsevier Science Publishers.

Sappington, D., J. Pfeifenberger, P. Hanser, and G. Basheda (2001) "Status and Trends of Performance-Based Regulation in the U.S. Electric Utility Industry," The Electricity Journal, 14: 71-79.

Sappington, D. and D. Weisman (1996a) Designing Incentive Regulation for the Telecommunications Industry. Cambridge, MA: MIT Press.

Sappington, D. and D. Weisman (1996b) "Potential Pitfalls in Empirical Investigations of the Effects of Incentive Regulation Plans in the Telecommunications Industry," Information Economics and Policy, 8: 125-140.

Sheshinski, E. (1976) "Price, Quality and Quantity Regulation in Monopoly Situations," Economica, 43: 127-137.

Spence, A. M. (1975) "Monopoly, Quality, and Regulation,” Bell Journal of Economics, 6: 417-429. 
State Telephone Regulation Report (2002a) "Rate Regulation of Local Providers in Northeastern and Mid-Atlantic States,”20, White Paper, February 15.

State Telephone Regulation Report (2002b) "Retail Rate Regulation of Local Providers in S.E., Great Lakes,” 20: 3-7, March 1.

State Telephone Regulation Report (2002c) "Retail Rate Regulation of Local Exchange Providers in Western U.S.," 20, White Paper, March 15.

Tardiff, T. and W. Taylor (1993) "Telephone Company Performance Under Alternative Forms of Regulation in the U.S.," National Economic Research Associates, mimeo, September 7.

Weisman, D. (2002) “Price Regulation and Quality," Kansas State University, mimeo, July.

Zimmerman, P. (2003) "Regional Bell Operating Company Entry Into Long-Distance and Non-Price Discrimination Against Rival Interexchange Carriers: Empirical Evidence from Panel Data," Applied Stochastic Models in Business and Industry, forthcoming. 